INTESTINAL INFECTION

\title{
Dietary fructo-oligosaccharides and lactulose inhibit intestinal colonisation but stimulate translocation of salmonella in rats
}

\author{
I M J Bovee-Oudenhoven, S J M ten Bruggencate, M L G Lettink-Wissink, R van der Meer
}

Gut 2003;52:1572-1578

See end of article for authors' affiliations

Correspondence to:

I M J Bovee-Oudenhoven, $\mathrm{PhD}$, Wageningen Centre for Food Sciences/NIZO food research, PO Box 20, 6710 BA Ede,

The Netherlands:

Ingeborg.Bovee@nizo.nl

Accepted for publication: 30 May 2003

\begin{abstract}
Background and aims: It is frequently assumed that dietary non-digestible carbohydrates improve host resistance to intestinal infections by stimulating the protective gut microflora. However, compelling scientific evidence from in vivo infection studies is lacking. Therefore, we studied the effect of several nondigestible carbohydrates on the resistance of rats to Salmonella enteritidis infection.

Methods: Rats ( $n=8$ per group) were fed "humanised" purified diets containing $4 \%$ lactulose, fructooligosaccharides (FOS), resistant starch, wheat fibre, or cellulose. After an adaptation period of 2 weeks the animals were orally infected with $S$ enteritidis. Supplement induced changes in faecal biochemical and microbiological parameters were studied before infection. Colonisation of salmonella was determined by studying the faecal excretion of this pathogen and translocation by analysis of urinary nitric oxide metabolites over time and classical organ cultures. Intestinal mucosal myeloperoxidase activity was determined to quantify intestinal inflammation after infection.

Results: Despite stimulation of intestinal lactobacilli and bifidobacteria and inhibition of salmonella colonisation, FOS and lactulose significantly enhanced translocation of this pathogen. These supplements also increased cytotoxicity of faecal water and faecal mucin excretion, which may reflect mucosal irritation. In addition, caecal and colonic, but not ileal, mucosal myeloperoxidase activity was increased in infected rats fed FOS and lactulose. In contrast, cellulose, wheat fibre, and resistant starch did not affect the resistance to salmonella.

Conclusions: In contrast to most expectations, FOS and lactulose impair the resistance of rats to intestinal salmonella infection. Obviously, stimulation of the endogenous lactobacilli and bifidobacteria is no guarantee of improved host defence against intestinal infections.
\end{abstract}

G strointestinal infections are still a major health problem and not only in developing countries. In Europe and the United States the annual incidence of (mostly foodborne) intestinal infections is more than $10 \%$. The growing resistance of pathogenic bacteria to antibiotics makes it important to develop ways to prevent and treat intestinal infections by other means. ${ }^{1}$ Dietary modulation of host resistance to intestinal infections might be an attractive alternative approach. By influencing the composition of gastrointestinal contents, diet affects the gastrointestinal survival of pathogens, ${ }^{23}$ the endogenous intestinal microflora, ${ }^{45}$ and the epithelial barrier function. ${ }^{6}$ These primary non-immunological host defences of the gastrointestinal tract are particularly important in withstanding the first encounter with a pathogen.

Despite the current keen interest in the preventative and even therapeutic efficacy of so-called functional foods to improve gut health, compelling scientific evidence substantiating the role of dietary components in strengthening host resistance is scarce. Human ${ }^{57}$ and animal $^{89}$ studies have shown that diet, and particularly non-digestible carbohydrates, affect the composition of the intestinal microflora and many of them suppose that consequences for host resistance are likely. Endogenous bifidobacteria and lactobacilli are claimed to be important for intestinal health, and increased numbers of these genera are assumed to improve the colonisation resistance to pathogens. ${ }^{7}{ }^{10}$ This assumption is largely an extrapolation of results obtained from in vitro experiments. Carbohydrate fermenting lactobacilli and bifidobacteria produce bactericidal organic acids (lactic acid and short chain fatty acids) and possibly other inhibitory compounds (for example, hydrogen peroxide and bacteriocins) which suppress growth of pathogens like salmonella in co-cultures. ${ }^{11}$ However, host defences against intestinal infections are not solely dependent on the composition and metabolic activity of the endogenous microflora but also depend on the barrier function of the intestinal mucosa, ${ }^{6}$ especially when invasive pathogens are involved. Thus, stimulation of the intestinal lactobacilli and bifidobacteria, or inducing a change in gut flora composition as such, is not directly a functional effect nor a direct health advantage. In our opinion, irrespective of their prebiotic effect, the contribution of non-digestible carbohydrates in increasing resistance to intestinal infections can only be verified in strictly controlled in vivo experiments including a challenge with a pathogen.

Therefore, the aim of the present study was to determine the effect of dietary non-digestible carbohydrates on the resistance of rats to intestinal colonisation and translocation of Salmonella enteritidis. Considering that the efficacy of nondigestible carbohydrates to improve resistance might depend on their fermentability, non-fermentable or low fermentable carbohydrates (cellulose and wheat fibre), as well as highly fermentable carbohydrates (resistant starch, fructo-oligosaccharides, and lactulose) were studied. S enteritidis was chosen as infective agent because it is a major cause of human foodborne infectious diarrhoea in industrialised countries ${ }^{12}$

Abbreviations: FOS, fructo-oligosaccharides; MPO, myeloperoxidase 
and we have shown earlier that this model is sensitive to dietary modulation. ${ }^{2}$

\section{MATERIALS AND METHODS First infection experiment: animals, diets, and oral pathogen administration}

The experimental protocol was approved by the animal welfare committee of Wageningen University, The Netherlands.

Specific pathogen free male Wistar rats (WU, Harlan, Horst, The Netherlands), 8 weeks old and with a mean body weight of $274 \mathrm{~g}$, were housed individually in metabolic cages in a room with controlled temperature $\left(22-24^{\circ} \mathrm{C}\right)$, relative humidity $(50-60 \%)$, and light/dark cycle (lights on from 6 am to $6 \mathrm{pm}$ ). Animals ( $\mathrm{n}=8$ per group) were fed a purified diet containing (per $\mathrm{kg}$ ): $200 \mathrm{~g}$ acid casein, $502 \mathrm{~g}$ glucose, $160 \mathrm{~g}$ partly hydrogenated palm oil, $40 \mathrm{~g}$ corn oil, $10 \mathrm{~g}$ cellulose, $35 \mathrm{~g}$ mineral mix (without calcium), ${ }^{13} 10 \mathrm{~g}$ vitamin mix, ${ }^{13} 3.44 \mathrm{~g} \mathrm{CaHPO}_{4} \cdot 2 \mathrm{H}_{2} \mathrm{O}$ (corresponding to $20 \mathrm{mmol}$ calcium/kg diet; Merck, Darmstadt, Germany), and $40 \mathrm{~g}$ non-digestible carbohydrates. The non-digestible carbohydrates added to the diet were either (extra) cellulose (purity 99\%; Arbocel, Minerals \& Chemicals Assistance, Zutphen, The Netherlands), wheat fibre (purity 97\%; Vitacel, Internatio, Zutphen, The Netherlands), resistant starch (purity 88\%; Hylon VII, National Starch and Chemical Company, Bridgewater, New Jersey, USA), fructo-oligosaccharides (FOS, purity 93\%; Raftilose P95, Orafti, Tienen, Belgium), or lactulose (crystalline powder, purity 98\%; Solvay Pharmaceuticals BV, Weesp, The Netherlands). Food and demineralised drinking water were supplied freely on demand. Food intake was recorded at least once per 2 days and body weight at least once per 4 days.

Animals were acclimatised to the housing and dietary conditions for 2 weeks, after which they were orally infected with a single dose of $S$ enteritidis (clinical isolate, phage type 4 according to international standards; B124l culture of NIZO food research). $S$ enteritidis was cultured and stored as described earlier. ${ }^{14}{ }^{15}$ All rats received $1 \mathrm{ml}$ of saline containing 3\% (wt/vol) sodium bicarbonate and $1 \times 10^{9}$ viable $S$ enteritidis, as determined by plate count on Brilliant Green Agar (Oxoid, Basingstoke, UK). The virulence of this strain is sustained by routine oral passage in Wistar rats.

\section{Microbiological analyses of faeces}

Immediately before and several days after $S$ enteritidis infection, fresh faecal samples were collected directly from the anus of the animals and analysed for viable salmonella by plating 10-fold dilutions on Modified Brilliant Green Agar (Oxoid) containing sulfamandelate (Oxoid) and incubating overnight at $37^{\circ} \mathrm{C}$, as described earlier. ${ }^{4}$ These fresh faecal samples were also cultured for lactobacilli and enterobacteria, as described previously. ${ }^{4}$ Faecal bifidobacteria were specifically determined by real time quantitative polymerase chain reaction (PCR) targeting a 110-bp transaldolase gene sequence as described and validated elsewhere. ${ }^{16}$ DNA was isolated from faeces using the QIAamp DNA stool mini kit (QIAgen, Westburg, Leusden, The Netherlands) following the manufacturer's recommendations. PCR primers were purchased from Amersham Pharmacia Biotech Custom DNA Synthesis Service (Roosendaal, The Netherlands). Taqman probes, containing a 5' FAM fluorescent reporter dye and a 3' TAMRA quencher dye, were synthesised by PE Applied Biosystems Custom Oligonucleotide Synthesis Services (Nieuwerkerk a/d IJssel, The Netherlands). Real time PCR was performed using the ABI Prism 7700 Sequence Detection System (PE Applied Biosystems, Nieuwerkerk a/d IJssel, The Netherlands). The Taqman Exogenous Internal Positive Control (IPC) Reagent (VIC probe; PE Applied Biosystems) was inserted in the PCR protocol in order to check for PCR efficiency and to rule out PCR inhibiting substances in the faecal DNA extracts. Universal Taqman PCR Master Mix was purchased from PE Applied Biosystems. DNA extracts of dilutions of suspensions of Bifidobacterium breve and Bifidobacterium infantis (cultures B655 and B65l of NIZO food research, respectively) were used to plot a mean standard curve from which the number of bifidobacteria in faeces, represented by the target transaldolase sequence in faecal DNA extracts, could be calculated. Control experiments showed that slope of the standard curve was not altered when these pure bifidobacterial cultures were added to rat faeces indicating that recovery was good. This real time PCR method for quantification of bifidobacteria was preferred over faecal culturing because the media described for cultivation of bifidobacteria do not equally support the growth of all of the bifidobacterium species encountered in faeces and therefore may bias results. ${ }^{17}$

\section{Biochemical analyses of faeces}

Faeces were quantitatively collected during 4 days just before $S$ enteritidis infection for chemical analyses. Faeces were freeze dried, weighed to determine daily faecal dry matter excretion, and subsequently ground to obtain homogeneous powdered samples. Relative faecal wet weight was determined as described earlier. ${ }^{14}$ Total faecal lactic acid was measured in freeze dried faeces with a colourimetric enzymatic kit (Boehringer Mannheim, Germany), as described elsewhere. ${ }^{14}$ Mucins were extracted from freeze dried faeces and quantified fluorimetrically, as described earlier. ${ }^{14}$ Standard solutions of $N$-acetylgalactosamine (Sigma) were used to calculate the amount of oligosaccharide side chains liberated from mucins. Faecal mucins are therefore expressed as $\mu \mathrm{mol}$ oligosaccharide equivalents. The recovery of porcine stomach mucin (Sigma) added to freeze dried faeces was $>90 \%$. Fresh faecal samples, collected 2 days before infection and on day five after infection, were immediately frozen at $-20^{\circ} \mathrm{C}$ until determination of short chain fatty acids by gas chromatography, as described by Tangerman et al. ${ }^{18}$

\section{$\mathrm{pH}$ and cytotoxicity of faecal water}

Freeze dried faeces was reconstituted to prepare faecal water of physiological osmolarity (300 mOsmol/l) as described elsewhere, ${ }^{2}$ except that the second centrifugation step was extended to $\mathrm{l}$ h at $14000 \mathrm{~g}$ (Eppendorf 5415) to achieve clear precipitation of sediment. After determination of $\mathrm{pH}$ at $37^{\circ} \mathrm{C}$, the cytotoxicity of faecal water was determined with an erythrocyte assay as previously described ${ }^{19}$ and validated earlier with intestinal epithelial cells. ${ }^{20}$ The incubations were of physiological ionic strength (154 mM) and buffered at pH 7.0 (final $100 \mathrm{mM}$ 3-N-morpholino-propanesulfonic acid; Sigma) to prevent acid induced haemolysis.

\section{Analysis of nitric oxide metabolites in urine}

Starting the day before infection, complete $24 \mathrm{~h}$ urine samples were collected, preserved, and analysed for the nitric oxide metabolites nitrite and nitrate $\left(\mathrm{NO}_{\mathrm{x}}\right)$ by a colourimetric method, ${ }^{21}$ as described earlier. ${ }^{4}$

\section{Second infection experiment: organ cultures and intestinal inflammation}

A second infection experiment was performed with specific pathogen free male Wistar rats (WU, Harlan, Horst, The Netherlands), 8 weeks old, and with a mean body weight of $234 \mathrm{~g}$. Animals ( $\mathrm{n}=8$ per group) were acclimatised, housed, fed the cellulose, FOS, or lactulose supplemented diets, and orally infected with $S$ enteritidis (dose $1 \times 10^{8}$ colony forming units) as described for the first infection experiment. Two days after oral infection, rats were killed by carbon dioxide 
inhalation. The spleen, mesenteric lymph nodes, and the liver were excised, homogenised in sterile saline, and plated on Modified Brilliant Green Agar (Oxoid) to quantify viable salmonella, as described previously..$^{15}$ In addition, the ileum (last $12 \mathrm{~cm}$ proximal to the ileocaecal valve), caecum, and colon were pulled out, longitudinally excised, and freed of their contents by extensive washing in sterile saline. The mucosa of these intestinal segments was scraped off using a spatula. Scrapings were suspended in $1 \mathrm{ml}$ sterile saline and stored at $-20^{\circ} \mathrm{C}$. Intestinal inflammation was determined by analysis of the myeloperoxidase (MPO) activity in the mucosal scrapings using a colourimetric assay as described by Grisham et al. ${ }^{22}$ One unit of activity was defined as the amount of enzyme present that produces a change in absorbance per min of 1.0 at $37^{\circ} \mathrm{C}$ in the final reaction volume containing sodium acetate. The recovery of purified MPO isolated from human leukocytes (Calbiochem, Darmstadt, Germany) added to the scrapings always exceeded $85 \%$. Protein content of the scrapings was determined spectrophotometrically using the BCA Protein Assay Kit (Pierce, Rockford, Illinois, USA) with bovine serum albumin (Sigma) as standard.

\section{Statistics}

Results of the first infection experiment are expressed as standard error of the mean values (SEM) ( $\mathrm{n}=7$ in the wheat fibre group and $n=8$ in the other diet groups). Differences between the means of the diet groups were tested for significance by analysis of variance (ANOVA). Additionally, Fisher's protected least significance difference test, modified for multiple comparisons, was used to identify dietary groups that differed from each other (two sided, $\mathrm{p}<0.05$; statistical package SPSS/PC + v2.0, SPSS Inc, Chicago, Michigan, USA). Results of the second infection experiment are expressed as mean values (SEM) $(\mathrm{n}=8$ for all groups). Differences between the means of the diet groups were tested for significance by ANOVA. Student's $t$ test was used to determine whether translocation of salmonella and mucosal inflammation of rats in the FOS and lactulose groups were significantly increased in comparison with the cellulose control group (one sided, $\mathrm{p}<0.05$ ).

\section{RESULTS}

\section{Growth and food intake of the animals}

One rat in the wheat fibre group was excluded from the study because of immediate substantial wasting $(5-10 \mathrm{~g} / \mathrm{d})$ for unknown reason. Animal growth was affected by the different diets, even before infection (fig 1). After infection,

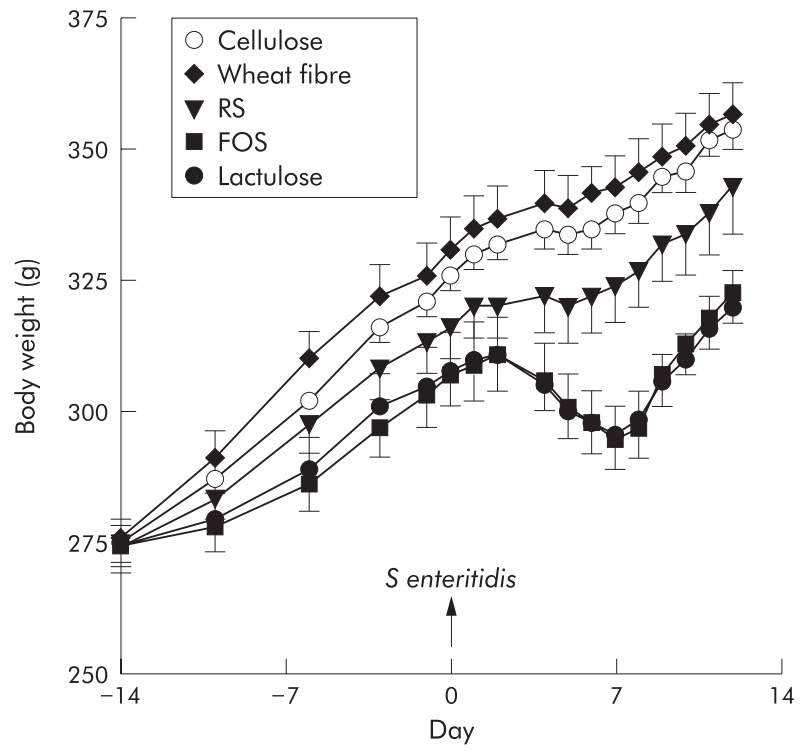

Figure 1 Effect of dietary cellulose, wheat fibre, resistant starch (RS), fructo-oligosaccharides (FOS), and lactulose on growth of the rats before and after oral administration of $1 \times 10^{9}$ colony forming units (CFU) of Salmonella enteritidis on day 0 . Results are expressed as means (SEM) ( $n=7$ in the wheat fibre group and $n=8$ in the other groups).

significant weight loss was only observed in the FOS and lactulose groups. Before infection, food consumption of rats fed lactulose (14.7 (0.6) g dry weight/d) and FOS (14.3 $(0.3) \mathrm{g} / \mathrm{d}$ ) was significantly less than that of rats fed resistant starch (16.7 (0.6) g/d), wheat fibre (17.9 (0.4) g/d), and

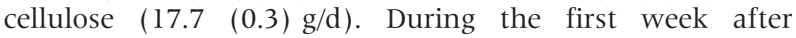
infection, food consumption was reduced by approximately $3 \mathrm{~g} / \mathrm{d}$ in all groups. Thereafter, mean daily food intake increased to pre-infection levels mentioned above. The reduced food intake of rats fed lactulose and FOS did not affect the faecal parameters and infection markers mentioned below, as the same results were obtained in an additional infection experiment with rats fed slightly restricted to achieve an equal food intake in the FOS and cellulose (control) groups (unpublished results).

\section{Effects of non-digestible carbohydrates on faecal parameters}

Resistant starch, and especially FOS and lactulose, decreased the daily excretion of faecal dry matter (table $1 ; p<0.05$ ). The

Table 1 Effect of dietary non-digestible carbohydrates on faecal parameters of rats before infection

\begin{tabular}{|c|c|c|c|c|c|}
\hline \multirow[b]{2}{*}{ Faecal parameter } & \multicolumn{5}{|c|}{ Non-digestible carbohydrate } \\
\hline & Cellulose & Wheat fibre & Resistant starch & FOS & Lactulose \\
\hline Dry weight excretion $(\mathrm{g} / \mathrm{d})$ & $1.04(0.03)^{*}$ & $1.04(0.04)^{*}$ & $0.45(0.03) \dagger$ & $0.28(0.04) \ddagger$ & $0.24(0.08) \neq$ \\
\hline Relative wet weight $(\%)$ & $46(3)^{*}$ & $49(3)^{*}$ & $69(2) \dagger$ & $73(1) \dagger$ & $67(1) \dagger$ \\
\hline $\mathrm{pH}$ of faecal water & $7.10(0.13)^{*}$ & $7.13(0.08)^{*}$ & $6.89(0.15)^{*}$ & $6.34(0.05) \dagger$ & $6.34(0.10) \dagger$ \\
\hline $\begin{array}{l}\text { Total SCFA ( } \mu \mathrm{mol} / \mathrm{g} \text { wet } \\
\text { faeces) }\end{array}$ & $38.8(5.7)^{*} \dagger$ & $38.1(4.7)^{*} \dagger$ & $49.2(8.2) \dagger$ & $31.1(3.4)^{*}$ & $27.8(3.4)^{*}$ \\
\hline Acetate $(\%$ of total $) \S$ & $80(2)^{*}$ & $82(1)^{*}$ & $80(4)^{*}$ & $72(1) \dagger$ & $78(2)^{*}$ \\
\hline Propionate ( $\%$ of total) & $17(1)^{*}$ & $16(1)^{*}$ & $19(3)^{*}$ & $26(1)+$ & $20(2)^{*}$ \\
\hline Butyrate (\% of total) & $2(1)^{*}$ & $1(1)^{*}$ & $1(1)^{*}$ & $1(1)^{*}$ & $1(1)^{*}$ \\
\hline $\begin{array}{l}\text { Lactic acid ( } \mu \mathrm{mol} / \mathrm{g} \text { wet } \\
\text { faeces) }\end{array}$ & $0.57(0.24)^{*}$ & $0.45(0.09)^{*}$ & $1.38(0.34) \dagger$ & $1.52(0.50) \dagger$ & $6.96(2.46) \ddagger$ \\
\hline
\end{tabular}

Results are expressed as means (SEM) ( $n=7$ in the wheat fibre group and $n=8$ in the other groups). Values in the same row not sharing the same superscript are significantly different $(p<0.05)^{\star} \dagger \ddagger$. §If the sum of the individual short chain fatty acids (SCFA) shown does not reach $100 \%$, it is because of the presence of small amounts ( $<1 \%$ of total SCFA) of isobutyrate, valerate, and isovalerate.

FOS, fructo-oligosaccharides. 


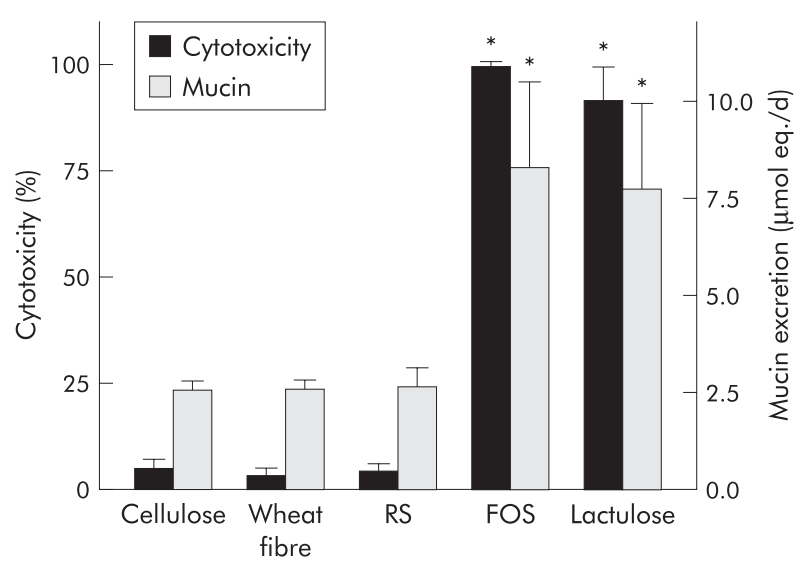

Figure 2 Effect of non-digestible carbohydrates on cytotoxicity of faecal water and daily faecal mucin excretion before infection of the rats. Cytotoxicity was determined with a haemolysis assay and mucins were measured fluorimetrically. Results are expressed as means (SEM) ( $n=7$ in the wheat fibre group and $n=8$ in the other groups). *These faecal parameters were significantly increased in the fructo-oligosaccharides (FOS) and lactulose group $(p<0.05)$. RS, resistant starch.

relative faecal wet weight of animals fed resistant starch, FOS, and lactulose was much higher than that of the cellulose and wheat fibre groups (table $1 ; \mathrm{p}<0.05$ ). Addition of FOS and lactulose to the diets decreased $\mathrm{pH}$ of faecal water when compared with the other non-digestible carbohydrates (table $1 ; \mathrm{p}<0.05$ ). No major differences between dietary groups were observed in the total short chain fatty acid concentration of faeces, except that FOS-fed rats had relatively less acetate and more propionate in their faeces (table $1 ; \mathrm{p}<0.05$ ). The total lactic acid concentration was highest in faeces of lactulose fed rats, intermediate in the FOS and resistant starch groups, and lowest in faeces of

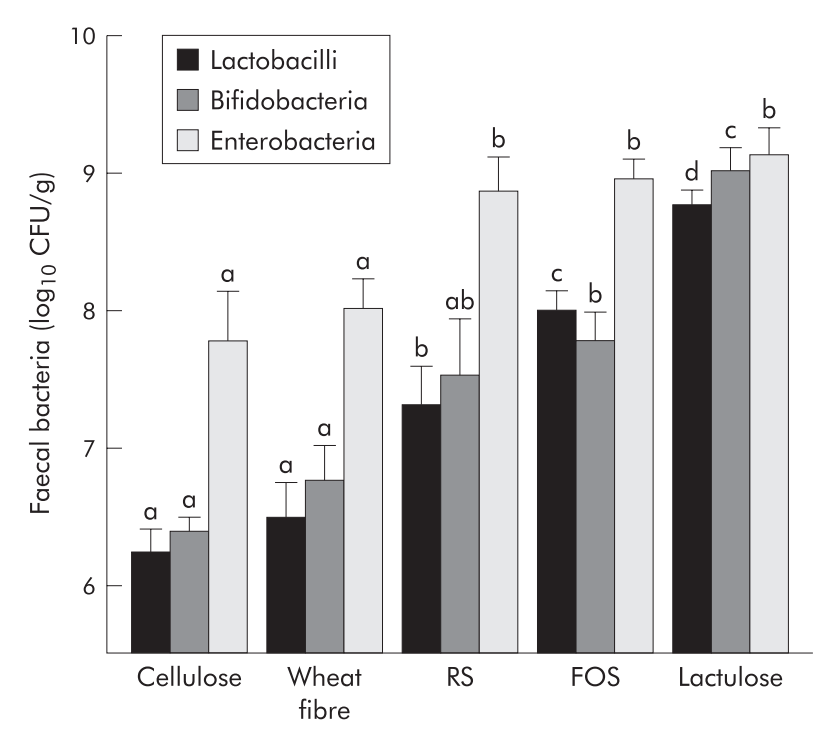

Figure 3 Effect of non-digestible carbohydrates on lactobacilli, bifidobacteria, and enterobacteria in faecal samples collected before infection of the rats. Lactobacilli were cultured anaerobically on Rogosa Agar and enterobacteria were cultured aerobically on Levine EMB Agar.

Bifidobacteria were determined by specific real time quantitative polymerase chain reaction (PCR). Results are expressed as means (SEM) ( $n=7$ in the wheat fibre group and $n=8$ in the other groups). Bars indicated by different letters are significantly different $(p<0.05)$. RS, resistant starch; FOS, fructo-oligosaccharides; CFU, colony forming units. wheat fibre and cellulose fed rats (table $1 ; \mathrm{p}<0.05$ ). Faecal mucin excretion was significantly stimulated by FOS and lactulose supplementation (fig 2). These oligosaccharides also greatly increased the cytotoxicity of faecal water (fig 2; $\mathrm{p}<0.05)$.

\section{Non-digestible carbohydrates and the intestinal microflora}

Compared with the cellulose and wheat fibre groups, a more than 100-fold increase in faecal lactobacilli was observed in rats fed the lactulose diet. These lactic acid bacteria were also stimulated by FOS and resistant starch, though to a lesser extent (fig 3; $\mathrm{p}<0.05$ ). FOS and especially lactulose increased the number of bifidobacteria (fig $3 ; \mathrm{p}<0.05$ ). Lactulose, FOS, and resistant starch also increased the number of enterobacteria in faeces (fig $3 ; \mathrm{p}<0.05$ ). The levels of these bacterial genera were not affected by $S$ enteritidis infection (data not shown).

\section{Differential effects of non-digestible carbohydrates on colonisation and translocation of salmonella, and on intestinal inflammation}

As expected, no salmonella could be detected in faeces collected before infection of the rats. Compared with the other diet groups, the FOS supplemented animals clearly had the best colonisation resistance to $S$ enteritidis, considering the reduced faecal shedding of this pathogen over time (fig 4; $\mathrm{p}<0.05)$. Though the lactulose group also tended to have lower faecal salmonella counts during the first days after infection, this was only significant from the cellulose, wheat fibre, and resistant starch groups on day four post-infection. Major differences were observed in the effects of nondigestible carbohydrates on the resistance to translocation of $S$ enteritidis, as measured by the infection induced urinary $\mathrm{NO}_{\mathrm{x}}$ excretion over time (fig 5 ). Peak urinary $\mathrm{NO}_{\mathrm{x}}$ excretion of the

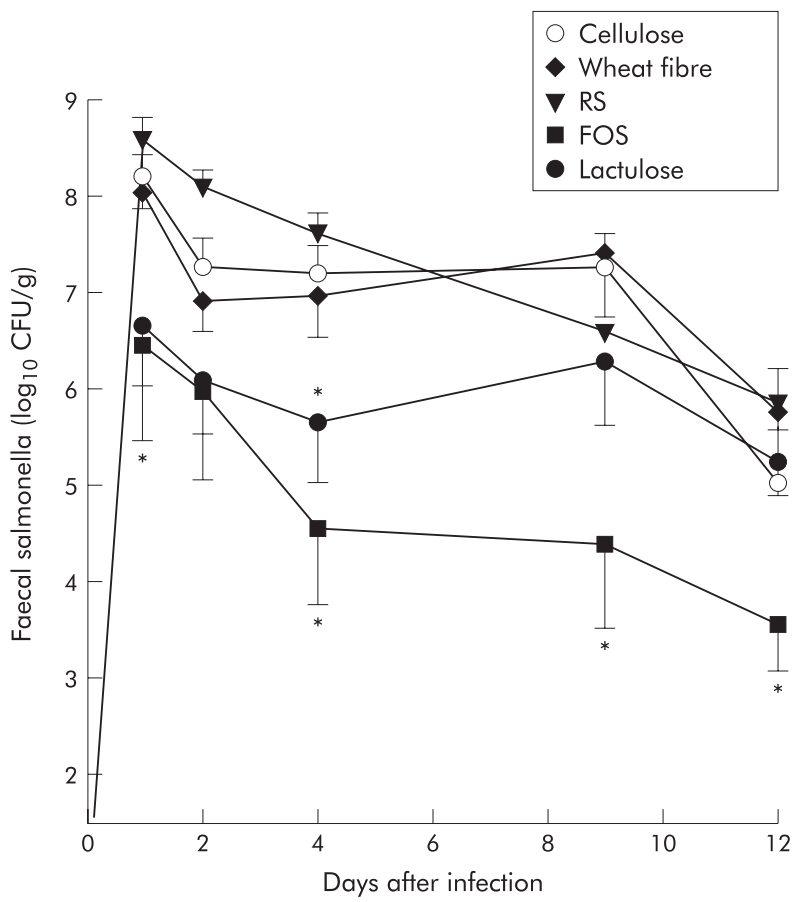

Figure 4 Effect of dietary cellulose, wheat fibre, resistant starch (RS), fructo-oligosaccharides (FOS), and lactulose on faecal Salmonella enteritidis excretion of rats after oral administration of $1 \times 10^{9}$ colony forming units (CFU) of $S$ enteritidis on day 0 . Results are expressed as means (SEM) ( $n=7$ in the wheat fibre group and $n=8$ in the other groups). *The indicated group is significantly different from all other groups at that time point $(p<0.05)$. 


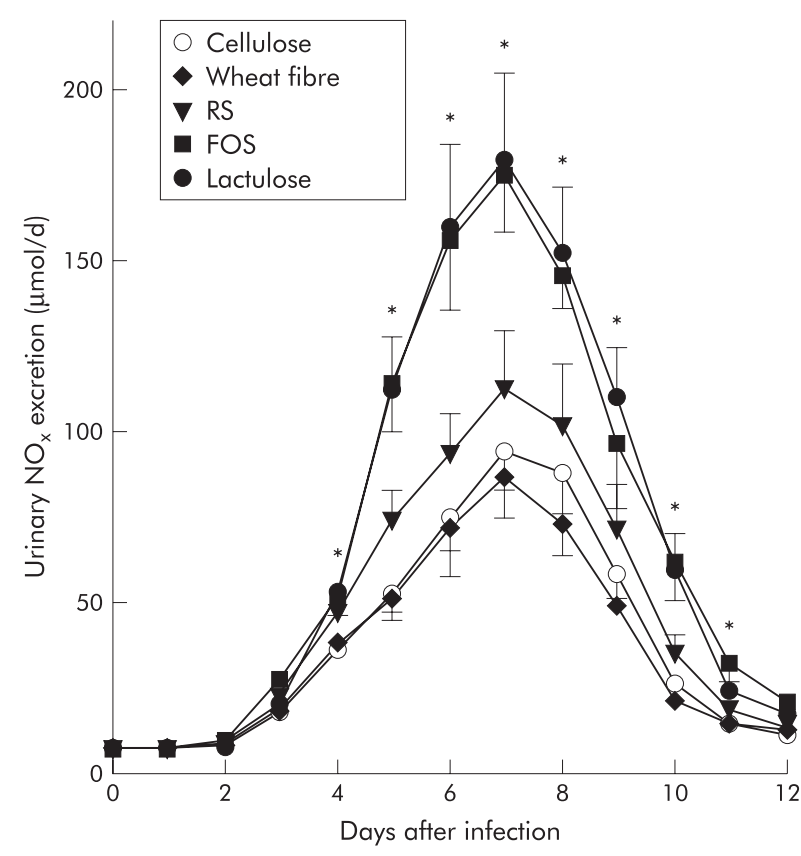

Figure 5 Effect of dietary cellulose, wheat fibre, resistant starch (RS), fructo-oligosaccharides (FOS), and lactulose on the kinetics of urinary $\mathrm{NO}_{x}$ excretion of rats after an oral challenge with $1 \times 10^{9}$ colony forming units of Salmonella enteritidis on day 0 . Results are expressed as means (SEM) ( $n=7$ in the wheat fibre group and $n=8$ in the other groups). ${ }^{*}$ Denotes that the FOS and lactulose groups are significantly different from all other groups at that time point $(p<0.05)$.

lactulose and FOS groups was twice as high as that of the cellulose, wheat fibre, and resistant starch groups (fig 5; $\mathrm{p}<0.05)$. The total infection induced urinary $\mathrm{NO}_{\mathrm{x}}$ excretion was 412 (49), 370 (46), 530 (74), 834 (81), and 835 (106) $\mu \mathrm{mol} / 12 \mathrm{~d}$ for the cellulose, wheat fibre, resistant starch, FOS, and lactulose group, respectively (the FOS and lactulose groups were significantly different from the other dietary groups). To validate that the strong infection induced increase in urinary $\mathrm{NO}_{\mathrm{x}}$ excretion in the FOS and lactulose group reflected increased intestinal translocation of salmonella, the second infection experiment was performed. The significantly increased numbers of viable salmonella in extra intestinal organs confirmed that dietary FOS and lactulose stimulated intestinal bacterial translocation (table 2). In addition, the caecal and colonic mucosal MPO activity was 2-3 fold higher in FOS and lactulose fed infected rats in comparison with rats on a cellulose-supplemented diet (fig 6; $\mathrm{p}<0.05$ ). Remarkably, dietary FOS and lactulose did not affect this marker of inflammation in the ileal mucosa of infected rats (fig 6).

Table 2 Effect of dietary non-digestible carbohydrates on viable salmonella counts in organs of rats two days after oral infection of the animals

\begin{tabular}{llll}
\hline & \multicolumn{3}{l}{ Salmonella counts in organ $\left(\log _{10} \mathrm{CFU} / \mathrm{g}\right)$} \\
\cline { 2 - 4 } $\begin{array}{l}\text { Non-digestible } \\
\text { carbohydrate }\end{array}$ & $\begin{array}{l}\text { Mesenteric } \\
\text { lymph nodes }\end{array}$ & Spleen & Liver \\
\hline Cellulose & $5.37(0.56)$ & $2.73(0.15)$ & $1.55(0.27)$ \\
FOS & $6.15(0.18)$ & $3.11(0.09)^{*}$ & $2.32(0.26)^{*}$ \\
Lactulose & $6.05(0.18)$ & $2.89(0.32)$ & $2.89(0.38)^{*}$ \\
\hline
\end{tabular}

Results are expressed as means (SEM) ( $n=8$ per group). *Denotes that the indicated group is significantly different from the cellulose group $(p<0.05)$.

CFU, colony forming units; FOS, fructo-oligosaccharides.

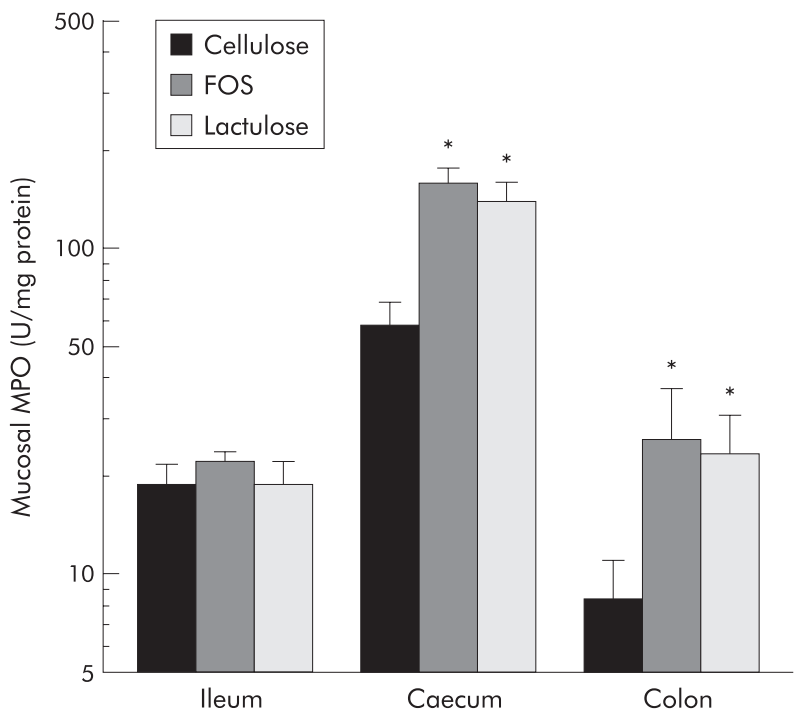

Figure 6 Effect of dietary cellulose, fructo-oligosaccharides (FOS), and lactulose on the specific activity of myeloperoxidase (MPO) in the ileal, caecal, and colonic mucosa of rats two days after oral infection of the animals with $1 \times 10^{8}$ colony forming units (CFU) of Salmonella enteritidis. Results are expressed as means (SEM) ( $n=8$ per group). Notice that the $y$ axis is a log scale. *Denotes that the FOS and lactulose group are significantly different from the cellulose group $(p<0.05)$.

\section{DISCUSSION}

The most striking result of the present study is that dietary lactulose and FOS improve the colonisation resistance to $S$ enteritidis, but concomitantly lower the resistance of rats to translocation of this invasive pathogen. No such effects were observed with resistant starch, wheat fibre, or cellulose supplementation of the diet. The colonisation resistance is inversely related to faecal pathogen excretion in time. ${ }^{23}$ So, prolonged excretion of high numbers in faeces upon oral infection indicates adherence and multiplication of the pathogen in the intestinal tract, whereas a rapid decline in faecal pathogen excretion reflects inability of the pathogen to colonise. Supplementation of the diet with lactulose and especially FOS decreases colonisation of $S$ enteritidis, as measured by the reduced faecal shedding of this pathogen over time (fig 4). At several time points after infection faecal excretion of $S$ enteritidis was approximately 100 -fold less in rats fed FOS in comparison to the cellulose, wheat fibre, and resistant starch groups. The oligosaccharides $\mathrm{FOS}^{24}$ and lactulose $\mathrm{e}^{25}$ are not hydrolysed by host digestive enzymes in the proximal small intestine but are rapidly fermented by the microflora residing in the caecum and colon. As a result, the endogenous gut flora is stimulated and intestinal contents are acidified due to the production of lactic acid and short chain fatty acids. ${ }^{26}$ Consequently, the colonisation of foodborne pathogens might be inhibited through enhanced competition for nutrients and mucosal adhesion $\operatorname{sites}^{27}$ and increased luminal killing of acid sensitive pathogens, like salmonella. ${ }^{14}$ Indeed, the present study showed that FOS and lactulose significantly lowered faecal $\mathrm{pH}$ (table 1) and increased the number of lactobacilli and bifidobacteria (fig 3). These lactic acid bacteria may contribute to host resistance as clinical investigations have shown that orally administered probiotic lactobacilli alleviate antibiotic associated diarrhoea ${ }^{28}$ and rotavirus enteritis. ${ }^{29}$ Besides a trophic effect of resistant starch, FOS, and lactulose on the endogenous lactobacilli and bifidobacteria, faecal enterobacteria were stimulated as well (fig 3). Accordingly, in our animal model we find no support for the claim that FOS (but also lactulose and resistant starch) can be classified as a 
prebiotic, since one of the current criteria that allow such classification is selective stimulation of potentially beneficial intestinal bacteria. ${ }^{7}$ The general opinion is that enterobacteria are not potentially beneficial because members of that bacterial family are involved in foodborne infectious disease ${ }^{30}$ and gut derived septicemia. ${ }^{31}$

Although colonisation of $S$ enteritidis was inhibited by FOS and to a lesser extent by lactulose, these oligosaccharides remarkably stimulated bacterial translocation to extra intestinal sites, as indicated by the strongly increased infection induced urinary $\mathrm{NO}_{\mathrm{x}}$ output (fig 5) and by higher viable salmonella counts in extra intestinal organs (table 2). The evident infection induced loss of body weight of rats fed FOS and lactulose also confirms that the systemic infection was most severe in these groups (fig 1). Classically, bacterial translocation is quantified by blood or organ cultures. However, organ cultures notably underestimate total bacterial translocation because the majority of translocated pathogens are rapidly killed by the innate immune system upon translocation. ${ }^{32}$ We have shown earlier that urinary $\mathrm{NO}_{\mathrm{x}}$ excretion correlates with organ cultures, but is a more sensitive and quantitative biomarker of intestinal bacterial translocation. ${ }^{2}{ }^{15}$ Recently, several other rodent ${ }^{33} 34$ and human ${ }^{35} 36$ studies have been reported, showing that serum or urinary $\mathrm{NO}_{\mathrm{x}}$ correlates with extra intestinal pathogen load and the severity of systemic infectious disease. Concordant with the stimulated translocation of $S$ enteritidis in the FOS and lactulose groups in the present study, the inflammatory response in the caecal and colonic mucosa was also greater in these infected rats than in their cellulose fed counterparts (fig 6). We have recently performed an additional study in rats fed a FOS supplemented diet. It should be mentioned that intestinal mucosal histology showed that mucosal inflammation was absent in FOS fed rats before oral infection with salmonella. However, mucosal inflammation of the caecum and colon was notably more severe in the FOS group after salmonella challenge in comparison with the infected cellulose control group (Ten Bruggencate et al, unpublished data).

At first sight, the detrimental effect of FOS and lactulose on the translocation resistance seems contradictory to their beneficial effect on the colonisation resistance. However, intestinal mechanisms responsible for colonisation resistance might be different from those determining translocation resistance. For instance, optimal functioning of the mucosal barrier is essential to prevent translocation and gut derived septicaemia. On the other hand, intestinal colonisation of a foodborne pathogen is likely to be more dependent on gut microbial ecology. The decreased faecal shedding of salmonella over time on the FOS and lactulose diets in the present study is probably a reflection of increased luminal killing of $S$ enteritidis. At the same time, these oligosaccharides obviously impair the gut mucosal barrier as indicated by the enhanced translocation of salmonella. The strongly increased cytotoxicity of faecal water of FOS and lactulose fed rats (fig 2) suggests that the intestinal mucosa was exposed to aggressive luminal contents, which might have led to epitheliolysis and impairment of the barrier function. The increased faecal output of mucin in these groups (fig 2) also points to irritation of the gut mucosa. The mucus layer (viscous gel of hydrated mucin glycoproteins) protects the intestinal epithelium from physical and chemical damage. As a defence mechanism, the intestinal mucosa is triggered to secrete more mucin in the presence of bacterial toxins ${ }^{37}$ and short chain fatty acids. ${ }^{38}$ High concentrations of short chain fatty acids can damage the intestinal epithelium, resulting in an increased permeability and epithelial cell proliferation. ${ }^{39} 40$ Under normal circumstances, the major site of salmonella translocation seems to be the ileal Peyer's patches, ${ }^{41}$ but this issue is still debated. ${ }^{42}$ Considering that fermentation of FOS and lactulose in the human ${ }^{24} 25$ and rat ileum ${ }^{43}$ is very limited, it is unlikely that these oligosaccharides facilitated translocation of $S$ enteritidis at that particular site. This is also indicated by the absence of FOS and lactulose induced ileal mucosal inflammation in infected rats of the present study (fig 6). Besides the ileum as entrance route, there is evidence from in vitro experiments that salmonella species can cross monolayers of epithelial cells by a transcellular and paracellular route. ${ }^{44}$ We speculate that these migration pathways are explicitly exploited by salmonella in the caecum and colon in conditions of enhanced production of organic acids due to rapid fermentation of FOS and lactulose. The significantly increased mucosal inflammation of the caecum and colon of FOS and lactulose fed rats infected with salmonella (fig 6) strongly points in that direction. Identification of the cytolytic components in intestinal contents after FOS and lactulose consumption and their effect on mucosal barrier in different regions of the intestinal tract (ileum versus caecum and colon) will be the subject of future research.

Dietary resistant starch did not improve the colonisation resistance to $S$ enteritidis in the present study, nor did it share the detrimental effect of FOS and lactulose on the translocation resistance to this pathogen. In addition, no increase in faecal mucin and luminal cytotoxicity was observed during resistant starch feeding. Like FOS and lactulose, dietary resistant starch is well fermented by the human ${ }^{45}$ and rat $^{46}$ gut microflora, as indicated by its absence in faeces. However, the fermentation rates of polymers are generally less than that of oligomers. ${ }^{47}{ }^{48}$ Thus resistant starch feeding leads to a more gradual and distributed intestinal fermentation and concomitant production of organic acids. ${ }^{49}$ This may have prevented damage to the caecal and colonic mucosal barrier as observed with FOS and the disaccharide lactulose.

Can these results be extrapolated to the human situation? Daily intake of fructose based non-digestible carbohydrates (mainly derived from wheat and onions) in Europe and the USA has been estimated at up to $10 \mathrm{~g} .{ }^{50}$ Assuming a daily dry food intake of about $500 \mathrm{~g}$, the total concentration of these particular non-digestible carbohydrates in an average Western human diet is about $2 \%$. This estimation does not take into account consumption of specific meals and products supplemented with inulin or FOS, typically 3-10 g per portion. ${ }^{50}$ In addition, the human diet still contains other non-digestible carbohydrates. In view of this, supplementation of the animal diets with $4 \%$ non-digestible carbohydrates (as in the present study) is likely realistic to the human situation.

As far as we know, no controlled in vivo infection experiments are reported in literature, besides an interesting recent human study of Cummings et al. ${ }^{51}$ Travellers to various high risk destinations for traveller's diarrhoea (frequently due to infection with non-invasive enterotoxigenic Escherichia coli) were either supplemented with FOS or placebo. Prevalence of self reported traveller's diarrhoea was $11 \%$ in the FOS group and $20 \%$ in the placebo group, which was borderline significant $(p=0.08)$. The reduced diarrhoea of FOS supplemented travellers likely indicates inhibition of intestinal pathogen colonisation, which agrees with the inhibitory effects of FOS on salmonella colonisation in our rat study (fig 4).

In conclusion, the present study shows that dietary FOS and lactulose improve the colonisation resistance of rats to Senteritidis, but concomitantly impair the intestinal resistance to translocation of this pathogen, in contrast to most expectations. The slowly fermentable non-digestible carbohydrates resistant starch, wheat fibre, and cellulose did 
not have this detrimental effect. Although increasing the number of lactobacilli and bifidobacteria in the gut by stimulating intestinal carbohydrate fermentation and enhancing the production of short chain fatty acids is often assumed to be beneficial for intestinal health and resistance to infections, the results of the present study clearly warrant concern about this concept. The current keen scientific and commercial interest in enhancement of host defence by socalled prebiotics stresses the importance to verify this unexpected finding by additional well controlled intervention studies.

\section{ACKNOWLEDGEMENTS}

The authors thank Maria Faassen-Peters and Wilma Blauw for expert biotechnical assistance and Martijn Katan for stimulating discussions.

\section{Authors' affiliations}

I M J Bovee-Oudenhoven, S J M ten Bruggencate, M L G LettinkWissink, R van der Meer, Wageningen Centre for Food Sciences/NIZO food research, Ede, The Netherlands

\section{REFERENCES}

1 Osterholm MT. Emerging infections-another warning. N Engl J Med 2000;342:1280-1.

2 Bovee-Oudenhoven IMJ, Termont DSML, Weerkamp AH, et al. Dietary calcium inhibits the intestinal colonization and translocation of salmonella in rats. Gastroenterology 1997;113:550-7.

3 Sprong RC, Hulstein MF, Van der Meer R. High intake of milk fat inhibits intestinal colonization of listeria but not of salmonella in rats. J Nutr 1999; 129:1382-9.

4 Bovee-Oudenhoven IM, Wissink ML, Wouters JT, et al. Dietary calcium phosphate stimulates intestinal lactobacilli and decreases the severity of a salmonella infection in rats. J Nutr 1999;129:607-12.

5 Kleessen B, Sykura B, Zunft HJ, et al. Effects of inulin and lactose on fecal microflora, microbial activity, and bowel habit in elderly constipated persons. Am J Clin Nutr 1997;65:1397-1402.

6 Shoda R, Mahalanabis D, Wahed MA, et al. Bacterial translocation in the rat model of lectin induced diarrhoea. Gut 1995;36:379-81.

7 Gibson GR. Dietary modulation of the human gut microflora using the prebiotics oligofructose and inulin. J Nutr 1999;129:1438S-41S.

8 Silvi S, Rumney CJ, Cresci A, et al. Resistant starch modifies gut microflora and microbial activity in human flora-associated rats inoculated with faeces from Italian and UK donors. J Appl Microbiol 1999;86:521-30.

9 Cresci A, Orpianesi C, Silvi S, et al. The effect of sucrose or starch-based diet on short-chain fatty acids and faecal microflora in rats. J Appl Microbiol 1999;86:245-50.

10 Salminen S, Bouley C, Boutron-Ruault MC, et al. Functional food science and gastrointestinal physiology and function. Br J Nutr 1998;80:S147-S71.

11 Drago L, Gismondo MR, Lombardi A, et al. Inhibition of in vitro growth of enteropathogens by new Lactobacillus isolates of human intestinal origin. FEMS Microbiol Letters 1997;153:455-63.

12 Alterkruse SF, Swerdlow DL. The changing epidemiology of foodborne diseases. Am J Med Sci 1996;311:23-9.

13 Reeves PG, Nielsen FH, Fahey GC. AIN-93 Purified diets for laboratory rodents: final report of the American Institute of Nutrition ad hoc writing committee on the reformulation of the AIN-76A rodent diet. J Nutr 1993; 123:1939-51.

14 Bovee-Oudenhoven IMJ, Termont DSML, Heidt PJ, et al. Increasing the intestinal resistance of rats to the invasive pathogen Salmonella enteritidis: additive effects of dietary lactulose and calcium. Gut 1997:40:497-504.

15 Oudenhoven IMJ, Klaasen HLBM, Lapré JA, et al. Nitric oxide-derived urinary nitrate as a marker of intestinal bacterial translocation in rats. Gastroenterology 1994;107:47-53.

16 Requena T, Burton J, Matsuki T, et al. Identification, detection, and enumeration of human Bifidobacterium species by PCR targeting the transaldolase gene. Appl Environ Microbiol 2002;68:2420-7.

17 Beerens $\mathrm{H}$. An elective and selective isolation medium for Bifidobacterium spp. Lett Appl Microbiol 1990;1 1:155-7.

18 Tangerman A, Nagengast FM. A gas chromatographic analysis of fecal shortchain fatty acids, using the direct injection method. Anal Biochem 1996;236: 1-8.

19 Bovee-Oudenhoven I, Termont D, Dekker R, et al. Calcium in milk and fermentation by yoghurt bacteria increase the resistance of rats to salmonella infection. Gut 1996;38:59-65.
20 Lapré JA, Termont DSML, Groen AK, et al. Lytic effects of mixed micelles of fatty acids and bile acids. Am J Phyiol 1992;263:G333-G7.

21 Green LC, Wagner DA, Glogowski J, et al. Analysis of nitrate, nitrite, and $\left[{ }^{15} \mathrm{~N}\right]$ nitrate in biological fluids. Anal Biochem 1982;126:131-8.

22 Grisham MB, Benoit JN, Granger DN. Assessment of leukocyte involvement during ischemia and reperfusion of intestine. Methods Enzymol 1990; 186:729-42.

23 Vollaard EJ, Clasener HAL. Colonization resistance. Antimicrob Agents Chemother 1994;38:409-14.

24 Andersson HB, Ellegård LH, Bosaeus IG. Nondigestibility characteristics of inulin and oligofructose in humans. J Nutr 1999;129:1428S-30S.

25 Conn HO, Lieberthal MM. The hepatic coma syndromes and lactulose, Baltimore, 1979:248-77.

26 Cummings JH, Macfarlane GT, Englyst HN. Prebiotic digestion and fermentation. Am J Clin Nutr 2001;73(suppl):415S-20S.

27 Hentges DJ. Role of the intestinal microflora in host defense against infection. In: Hentges DJ, ed. Human intestinal microflora in health and disease. New York: Academic Press, 1983:311-31.

28 Siitonen S, Vapaatalo H, Salminen S, et al. Effect of lactobacillus GG yoghurt in prevention of antibiotic associated diarrhoea. Ann Med 1990;22:57-9.

29 Kaila M, Isolauri E. Nutritional management of acute diarrhea. Nutr Today 1996;31:16S-8S.

30 Karch $\mathbf{H}$, Bielaszewska $M$, Bitzan $M$, et al. Epidemiology and diagnosis of Shiga toxin-producing Escherichia coli infections. Diagn Microbiol Infect Dis 1999;34:229-43

31 Diekema DJ, Pfaller MA, Jones RN, et al. Survey of bloodstream infections due to Gram-negative bacilli: frequency of occurrence and antimicrobial susceptibility of isolates collected in the United States, Canada, and Latin America for the SENTRY Antimicrobial Surveillance Program, 1997. Clin Infect Dis 1999;29:595-607.

32 Gianotti L, Alexander JW, Pyles T, et al. Arginine-supplemented diets improve survival in gut-derived sepsis and peritonitis by modulating bacterial clearance. Ann Surg 1993;217:644-54.

33 Bories C, Sherman E, Bories PN. Serum and tissue nitrate levels in murine visceral leishmania correlate with parasite load but not with host protection. Trans R Soc Trop Med Hyg 1997;91:433-6.

34 Sprong RC, Hulstein MFE, Van der Meer R. Quantifying translocation of Listeria monocytogenes in rats by using urinary nitric oxide-derived metabolites. Appl Environ Micriobiol 2000;66:5301-5.

35 Forte $\mathbf{P}$, Dykhuizen RS, Milne E, et al. Nitric oxide synthesis in patients with infective gastroenteritis. Gut 1999:45:355-61.

36 Krafte-Jacobs B, Brilli R, Szabo C, et al. Circulating methemoglobin and nitrite/nitrate concentrations as indicators of nitric oxide overproduction in critically ill children with septic shock. Crit Care Med 1997;25:1588-93.

37 Moore BA, Sharkey KA, Mantle M. Neural mediation of cholera toxin-induced mucin secretion in the rat small intestine. Am J Physiol 1993:265:G1050-G6.

38 Barcelo A, Claustre J, Moro F, et al. Mucin secretion is modulated by luminal factors in the isolated vascularly perfused rat colon. Gut 2000;46:218-24.

39 Rémésy C, Levrat MA, Gamet L, et al. Cecal fermentations in rats fed oligosaccharides (inulin) are modulated by dietary calcium level. Am J Physiol 1993;264:G855-G62.

40 Wasan HS, Goodlad RA. Fibre-supplemented foods may damage your health. Lancet 1996;348:319-20.

41 Carter PB, Collins FM. The route of enteric infection in normal mice. J Exp Med 1974;139:1189-203.

42 Hughes EA, Galán JE. Immune response to salmonella: location, location, location? Immunity 2002;16:325-8.

43 Heijnen AM, Brink EJ, Lemmens AG, et al. Ileal pH and apparent absorption of magnesium in rats fed on diets containing either lactose or lactulose. Br J Nutr 1993;70:747-56.

44 Kops SK, Lowe DK, Bement WM, et al. Migration of Salmonella typhi through intestinal epithelial monolayers: an in vitro study. Microbiol Immunol 1996;40:799-811.

45 Hylla S, Gostner A, Dusel G, et al. Effects of resistant starch on the colon in healthy volunteers: possible implications for cancer prevention. Am J Clin Nutr 1998;67:136-42.

46 Morita T, Kasaoka S, Hase K, et al. Psyllium shifts the fermentation site of highamylose cornstarch toward the distal colon and increases fecal butyrate concentration in rats. J Nutr 1999:129:2081-7.

47 Christl SU, Murgatroyd PR, Gibson GR, et al. Production, metabolism and excretion of hydrogen in the large intestine. Gastroenterology 1992;102:1269-77.

48 Livesey G, Johnson IT, Gee JM, et al. Determination of sugar alcohol and polydextrose absorption in humans by the breath hydrogen $\left(\mathrm{H}_{2}\right)$ technique: the stoichiometry of hydrogen production and the interaction between carbohydrates assessed in vivo and in vitro. Eur J Clin Nutr 1993;47:419-30.

49 Brighenti F, Casiraghi MC, Pellingrini N, et al. Comparison of lactulose and inulin as reference standard for study of resistant starch fermentation using hydrogen breath test. Ital J Gastroenterol 1995;27:122-8.

50 Coussement PAA. Inulin and oligofructose: safe intakes and legal status. J Nutr 1999; 129:1412S-17S.

51 Cummings JH, Christie S, Cole TJ. A study of fructo oligosaccharides in the prevention of travellers' diarrhoea. Aliment Pharmacol Ther 2001;15:1139-45. 